\title{
O fenômeno do estresse em professores do Ensino Fundamental: uma revisão
}

\section{integrativa}

\author{
The phenomenon of stress in Elementary School teachers: an integrative review \\ El fenómeno del estrés en los Profesores de Primaria: una revisión integradora
}

Recebido: 02/02/2021 | Revisado: 05/02/2021 | Aceito: 06/02/2021 | Publicado: 14/02/2021

\author{
Mariana Dal Ben \\ ORCID: https://orcid.org/0000-0002-6279-5318 \\ Fundação Educacional do Município de Assis, Brasil \\ E-mail: mariana_dalben@hotmail.com \\ Daniel Augusto da Silva \\ ORCID: https://orcid.org/0000-0002-2716-6700 \\ Fundação Educacional do Município de Assis, Brasil \\ E-mail: daniel.augusto@unifesp.br
}

\begin{abstract}
Resumo
Objetivo: identificar os fatores de risco e proteção, e estratégias de enfrentamento do estresse em professores do ensino fundamental em escolas públicas. Metodologia: trata-se de estudo de abordagem qualitativa, exploratória bibliográfica, com síntese de produções cientificas através de revisão integrativa. A busca de artigos foi realizada entre os meses de maio a agosto de 2020, utilizando-se os Descritores de Saúde: Estresse Psicológico; Professores Escolares, e o operador boleano "AND". Resultados: foram analisados 10 artigos, publicados no ano de 2020. Percebe-se que os professores passam por diversos estressores, que estão diariamente os acompanhando e que perpassam as mais diversas ordens como: salas super lotadas, indisciplina dos alunos, falta de estrutura física e material, falta de atenção e compromisso dos alunos com a escola, fazendo com que se sintam desvalorizados, desrespeitados e muitas vezes culpabilizados, por não darem conta de abarcar todas as funções que lhe são impostas. Essas condições de trabalho, nas quais os professores usam de todas as suas capacidades físicas, cognitivas e afetivas para atingir os objetivos da produção escolar podem acabar gerando um grande esforço de suas funções psicofisiológicas. Considerações finais: O estresse em professores do ensino fundamental é real, e pode levar a sério problemas de saúde mental e física desses profissionais.
\end{abstract}

Palavras-chave: Estresse ocupacional; Estresse psicológico; Professores escolares; Ensino fundamental e médio.

\begin{abstract}
Objective: to identify risk and protection factors, and strategies for coping with stress in elementary school teachers in public schools. Methodology: this is a qualitative, exploratory bibliographic study, with synthesis of scientific productions through an integrative review. The search for articles was carried out between May and August 2020, using the Health Descriptors: Psychological Stress; School Teachers, and the Boolean operator "AND". Results: 10 articles were analyzed, published in the year 2020. It is noticed that teachers go through several stressors, who are accompanying them daily and that go through the most diverse orders such as: overcrowded rooms, students' indiscipline, lack of physical structure and material, lack of attention and commitment of students to the school, making them feel devalued, disrespected and often blamed, for not being able to cover all the functions that are imposed on them. These working conditions, in which teachers use all of their physical, cognitive and affective abilities to achieve the goals of school production, can end up generating a great strain on their psychophysiological functions. Final considerations: The stress in elementary school teachers is real, and can take these mental and physical health problems seriously.
\end{abstract}

Keywords: Occupational stress; Stress psychological; School teachers; Education primary and secondary.

\section{Resumen}

Objetivo: identificar factores de riesgo y protección, y estrategias para afrontar el estrés en docentes de primaria en escuelas públicas. Metodología: se trata de un estudio bibliográfico cualitativo, exploratorio, con síntesis de producciones científicas a través de una revisión integradora. La búsqueda de artículos se realizó entre mayo y agosto de 2020, utilizando los Descriptores de Salud: Estrés Psicológico; Maestros de la escuela y el operador booleano "AND". Resultados: Se analizaron 10 artículos, publicados en el año 2020. Se advierte que los docentes pasan por varios estresores, que los acompañan a diario y que pasan por los más diversos órdenes como: aulas superpobladas, indisciplina de los alumnos, falta de estructura y material, falta de atención y compromiso de los alumnos con la escuela, haciéndolos sentir devaluados, irrespetados y muchas veces culpables, por no poder cubrir todas las funciones que se les imponen. Estas condiciones laborales, en las que los docentes emplean todas sus capacidades físicas, cognitivas y afectivas para alcanzar las metas de producción escolar, pueden llegar a generar una gran tensión en sus funciones psicofisiológicas. 
Consideraciones finales: El estrés en los maestros de la escuela primaria es real y puede tomar en serio estos problemas de salud mental y física.

Palabras clave: Estrés laboral; Estrés psicológico; Maestros; Educación primaria y secundaria.

\section{Introdução}

O ser humano durante seus dias desenvolve atividades diárias nas quais o mesmo já está habituado e as faz com facilidade. Isso se dá pelo fato de que essas atividades já foram aprendidas uma vez ao longo da vida do indivíduo. Toma-se como exemplo as atividades de higienização e alimentação que são realizadas ao longo do dia quando possível. Estas atividades realizadas automaticamente são rápidas e podem passar despercebidas, quando uma pessoa vive sem uma perturbação, pode-se dizer que a pessoa está totalmente adaptada à rotina (Vaz-Serra, 2000).

Por vezes pode haver circunstâncias que fazem o ser-humano sair da rotina e que podem exigir uma nova adaptação, e quando essas circunstâncias são semelhantes às antigas podem ocorrer somente um pequeno sobressalto adaptativo ocasional. Contudo nem sempre um indivíduo sabe como se adaptar as essas novas circunstâncias, e dessa não adaptação é de onde o estresse aparece (Vaz-Serra, 2000).

$\mathrm{Na}$ ausência de adaptação às situações, o estresse patológico é instalado, de forma que gera distúrbios transitórios ou doenças graves. O estresse, conforme o modelo quadrifásico proposto por Lipp, tem seu desenvolvimento em quatro fases: alarme/alerta, resistência, quase-exaustão e exaustão (Lipp, Costa, \& Nunes, 2017; Cardoso, Gomes, Pereira Junior, \& Silva, 2019).

A primeira fase tem início pela produção de adrenalina, e inicia-se a reação de luta ou fuga, com sinais e sintomas que incluem dificuldade em dormir de forma muito acentuada em consequência do aumento da adrenalina presente na corrente sanguínea, aumento da libido, grande produtividade e criatividade no trabalho, tensão muscular, taquicardia, sudorese, anorexia, tensão mandibular, dispneia, euforia, irritabilidade. Em seguida vem à segunda fase, a fase de resistência, na qual o indivíduo ainda se encontra exposto ao agente estressor, porém, já foram mobilizadas reservas fisiológicas para propiciar o aumento à resistência ao estresse, com sinais e sintomas que compreendem diminuição da libido, produtividade e criatividade voltam ao nível usual, porém com dificuldades para novas ideias, cansaço sem relação com tempo de sono e repouso, excesso de preocupação e exteriorização desta preocupação relacionada a fonte de seu estresse (Cardoso, Gomes, Pereira Junior, \& Silva, 2019).

$\mathrm{Na}$ terceira fase, a fase de quase-exaustão, caracteriza-se por insônia, perda acentuada da libido, queda drástica da criatividade e produtividade no trabalho, cansaço atrelado a sensação de desgaste físico, perda de memória, surgimento de doenças, problemas ginecológicos, ansiedade diária, perda do desejo de socialização, desinteresse pela vida. E por fim, na quarta e última fase como fase de exaustão, caracterizada por sensação de consumo total da energia do indivíduo, com necessidade de intervenção externa para reposição de fontes de energia adaptativa, como os medicamentos. Cita-se que os sinais e sintomas são a insônia, diminuição do tempo de sono e repouso, quase inexistência da libido, perda de interesse pelo trabalho, desgaste e cansaço intenso, inexistência de socialização, perda do senso de humor, apatia, desejo de morte, surgimento de doenças graves como depressão, úlceras, pressão alta, diabetes, infarto, entre outras, e até a morte (Cardoso, Gomes, Pereira Junior, \& Silva, 2019).

Nos últimos anos o estresse vem sendo bastante observado, porque ele é silencioso e às vezes passageiro, porém a partir do momento que ele deixa de se tornar passageiro e fica um pouco mais frequente do que o normal pode trazer riscos à saúde e a qualidade de vida do indivíduo. De maneira geral o bem-estar da população tem sido muito preocupante, as pessoas vivem sempre na correria, em busca para dar conta de tudo e de todos seus problemas, e isso acaba sendo preocupante demais porque através de tudo isso pode desencadear o estresse que leva a outras doenças (Nunes, Troyan Junior, Barreto, \& França Junior, 2017; Gomes, Pereira Junior, Cardoso, \& Silva, 2020). 
$\mathrm{Na}$ área da educação foi comprovado um crescimento ao número de sobrecarga à saúde dos professores, sendo constantemente relacionados às especificas condições de trabalho. Aproximadamente $70 \%$ dos profissionais de educação no Brasil apresentam indicativos de exaustão emocional, configurando os quadros de intensa depressão como o maior motivo para o afastamento desses profissionais dos locais de trabalho (Pereira, Teixeira, Andrade, Bleyer, \& Lopes, 2014). Os profissionais da educação são mais expostos a ambientes conflituosos e de alta exigência, reuniões, funções administrativas, atividades adicionais, orientações de alunos, violência (com relatos de ameaças verbais e físicas), bem como limitação de tempo para realização das atividades.

Alguns comportamentos estressantes em salas de aulas tais como alunos lendo revistas ou interrompendo o andamento da aula com atitudes infantis, brincadeiras e com declarações explicitas, por parte dos alunos, de que sabem que serão aprovados no fim do ano. Além disso, está inserido num contexto de mudanças em que alterações ambientais (políticas, econômicas, sociais e culturais) e as pressões decorrentes de determinadas tarefas têm alterado experiências de trabalho e seus significados. Essa situação estressante leva a repercussões na saúde física e mental e no desempenho desses profissionais (Pinotti, 2005; Carlotto, Dias, Batista, \& Diehl, 2015).

Neste sentido, este estudo tem por objetivo identificar os fatores de risco e proteção, e estratégias de enfrentamento do estresse em professores do ensino fundamental em escolas públicas.

\section{Metodologia}

Trata-se de estudo de abordagem qualitativa, exploratória bibliográfica, com síntese de produções cientificas através de revisão integrativa. Para este estudo, a questão norteadora foi: Quais as causas e consequências da ocorrência do estresse em professores escolares?

Foram selecionados artigos publicados e disponibilizados pela Biblioteca Virtual em Saúde (BVS), que abriga as bases de dados LILACS (Literatura Latino-Americana e do Caribe em Ciências da Saúde); BDENF (Base de Dados de Enfermagem); MEDLINE (Literatura Internacional em Ciências da Saúde); e CINAHL (Cummulative Index to Nursing and Allied Health Literature), e no Google Acadêmico.

A busca de artigos foi realizada entre os meses de maio a agosto de 2020, utilizando-se os Descritores de Saúde: Estresse Psicológico; Professores Escolares, e o operador boleano "AND”.

Os critérios de inclusão para seleção da amostra de artigos foram: artigos que abordassem a temática do estresse em professores escolares, apontando as causas e consequências do mesmo, indexados nas bases de dados selecionadas para o estudo e publicados no primeiro semestre de 2020, em português.

Os critérios de exclusão foram: artigos completos indisponíveis, artigos de revisão de literatura, integrativa ou sistemática, dissertações e teses.

A busca e a seleção dos artigos basearam-se no Sistema GRADE, que avalia a qualidade da evidência e a força de recomendação para tomada de decisão em saúde (Brasil, 2014).

Os procedimentos de busca e número de artigos analisados são apresentados na Figura 1. 
Figura 1. Procedimentos de busca e total de artigos analisados. Assis, SP, Brasil, 2020.

\section{Busca com descritores} selecionados

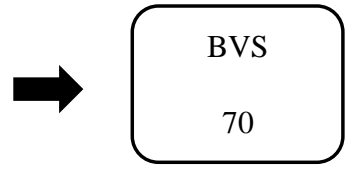

Google Acadêmico

$$
21.300
$$

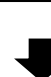

Incluídos: artigos

escolhidos em português,

texto completo, publicados em 2020

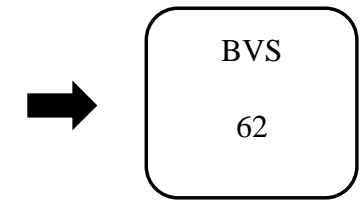

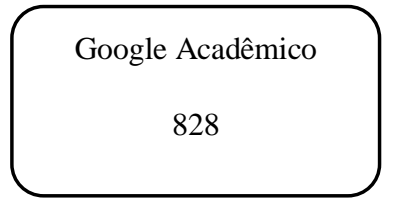

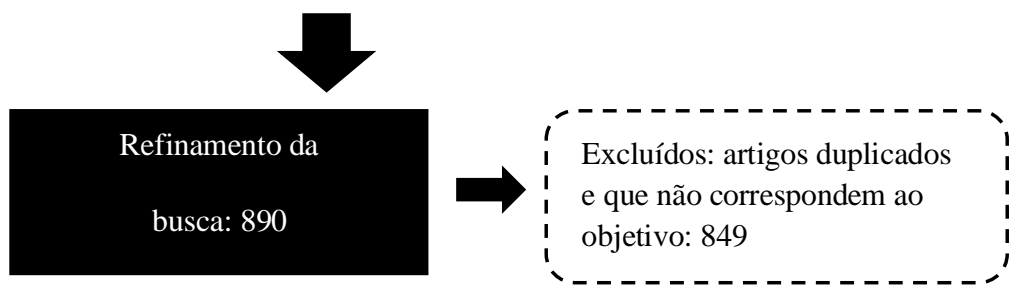

Selecionados a partir da

leitura dos títulos e resumos
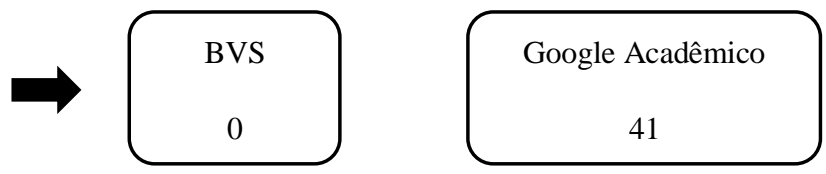

Resultado da seleção após leitura na integra

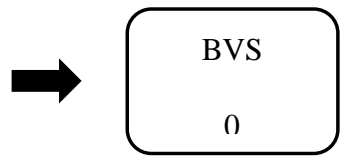

Google Acadêmico

10

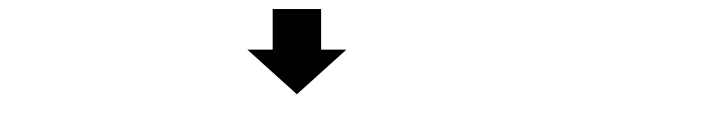

\section{Seleção final: 10}

Fonte: Autores.

\section{Resultados}

A Tabela 1 foi elaborada para sistematizar e organizar as informações constituídas nos artigos utilizados. Foram analisados 10 artigos, publicados no ano de 2020. As demais informações estão disponíveis na referida tabela.

Tabela 1. Apresentação dos resultados da revisão integrativa. Assis, SP, Brasil, 2020.

\begin{tabular}{ccccc}
\hline $\begin{array}{c}\text { Referência } \\
\text { Nível de } \\
\text { evidência } \\
\text { (GRADE) }\end{array}$ & Metodologia & Fatores de risco & $\begin{array}{c}\text { Fatores de } \\
\text { proteção }\end{array}$ & $\begin{array}{c}\text { Estratégias de } \\
\text { enfrentamento }\end{array}$ \\
\hline $\begin{array}{l}\text { Silva \& Fischer, } \\
2020\end{array}$ & $\begin{array}{l}\text { Descritivo exploratório, com 29 } \\
\text { professores. Entrevista realizada } \\
\text { através de codificação temática } \\
\text { com auxílio do software }\end{array}$ & $\begin{array}{l}\text { - Não prestar atenção; } \\
\text { - Frustração; } \\
\text { MAXQDA 12. Violência explícita; } \\
\text { Muito baixo }\end{array}$ & $\begin{array}{l}\text { - Levar o trabalho para casa; } \\
\text { trabalho com vida } \\
\text { pessoal; }\end{array}$ & $\begin{array}{l}\text { Conteúdo não } \\
\text { abordado. }\end{array}$ \\
\hline $\begin{array}{c}\text { Referência } \\
\text { Nível de } \\
\text { evidência } \\
\text { (GRADE) }\end{array}$ & Metodologia & Fatores de risco & Fatores de \\
proteção & Estratégias de \\
enfrentamento
\end{tabular}




\begin{tabular}{ll}
\hline Lucena \& & $\begin{array}{l}\text { Descritivo exploratório, com 10 } \\
\text { professores. Entrevista realizada }\end{array}$ \\
Muito baixo 2020. & $\begin{array}{l}\text { através de um questionário } \\
\text { sociodemográfico e entrevista } \\
\text { semiestruturada. }\end{array}$
\end{tabular}

\begin{tabular}{ll}
\hline $\begin{array}{l}\text { Santos, Espinosa, } \\
\text { \& Marcon, 2020. }\end{array}$ & $\begin{array}{l}\text { Descritivo exploratório, com } 326 \\
\text { professores. Foram realizadas } \\
\text { estatísticas descritivas de } \\
\text { frequência de tendência central e } \\
\text { dispersão e análises inferenciais } \\
\text { com testes de Wilcoxon, Mann- }\end{array}$ \\
& $\begin{array}{l}\text { Whitney e Kruskal-Wallis. } \\
\text { Muito baixo }\end{array}$ \\
\hline $\begin{array}{l}\text { Lourençitivo exploratório, com 10 } \\
\text { Valente, \& } \\
\text { Correa, 2020. }\end{array}$ & $\begin{array}{l}\text { semiestruturada com instrumento } \\
\text { elaborado pelos autores. }\end{array}$ \\
Muito baixo &
\end{tabular}

Muito baixo

Lourenço, Pérez-

Nebra, Ferreira,

\& Kohlsdorf,

2020.

Descritivo exploratório, com 366
reassores. A coleta de dados foi
elaborada através de questionários
elos autores.

- Falta de estrutura física;

- Superlotação das salas de aula;
- Se sentem
acolhidos pel

escola;

- Gostam do

alunado;

- Não existe

histórico de brigas e

discussões

Conteúdo não

abordado

- Transtorno mental comum;

- Queixa de sintomas

osteomuscular.
- Ter autocontrole;

- Praticar atividades

físicas;

- Ouvir músicas:
- Assédio moral;

- Agressividade dos alunos;

- Desvalorização da figura

docente;

- Doenças psicossomáticas;

- Carga horária excessiva;

- Exaustão emocional;

- Liderança ética;

- Perda de capacidade para

completar o trabalho;

- Concentração no trabalho;

Muito baixo

Lorenzo, Alves, \& Silva, 2020.

Descritivo exploratório, com 13

docentes. Realizado Questionário

Sociodemográfico, Inventário da

Muito baixo

Síndrome de Burnout e

Questionário de Satisfação no Trabalho S20/23

- Carga horária excessiva;

- Baixo salário;

- Salas super lotadas;

- Restrições de materiais

didáticos

- Baixo salário;

- Sobrecarga de trabalho;

Descritivo exploratório, com 13

professores. Como instrumento

para coleta de dados, foi utilizado

2020.

Muito baixo

Correa \& Leão,

2020. um questionário elaborado pelos autores.

Muito baixo

Ribeiro, 2020.

Muito baixo

\section{Descritivo exploratório, com 555} docentes. Utilizou com instrumentos de avaliação a Escala

Toulousaine de Estresse e

Toulousaine de Coping com auxílio do software SPHINX.

Descritivo exploratório, com 95 professores. Aplicação de questionário socio demográfico, e a aplicação da Escala de Vulnerabilidade ao Estresse no Trabalho.
- Desvalorização docente;

- Cobranças curriculares;

- Indisciplina dos alunos;

- Indisciplina e falta de respeito dos alunos;

- Falta de apoio familiar;

- Falta de apoio da instituição;

- Doenças psicossomáticas;

- Jornada exaustiva;

- Cansaço excessivo;

- Dificuldade de conciliar vida

pessoal e profissional;

- Falta de tempo;

- Excesso de cobrança;

- Organização do $\quad$ - Terapia;
trabalho;

trabalho;

$\begin{array}{ll}\text { Conteúdo não } & \begin{array}{l}\text { Conteúdo não } \\ \text { abordado }\end{array}\end{array}$

- Melhoria de Conteúdo não
condição de abordado

trabalho;

- Melhoria nas

relações interpessoais;

- Valorização;

- Respeito;

- Apoio da família;

- Cooperação entre pares;

- Andar de bicicleta; - Praticar esportes;

- Dançar;

- Caminhar;

- Correr;

- Nadar;

$\begin{array}{ll}\begin{array}{l}\text { Conteúdo não } \\ \text { abordado }\end{array} & \begin{array}{l}\text { Conteúdo não } \\ \text { abordado }\end{array}\end{array}$

- Medidas para prevenir o mal-estar docente; abordado abordado

Conteúdo não Estratégias de
enfrentamento

\section{Referência \\ Nível de \\ evidência \\ (GRADE)}

Silva, Sadoyama, Descritiva exploratória, com 81 Sousa, \& Leal, 2020.

Muito baixo professores. Para essa pesquisa, foram utilizados Inventário de Stress para Adultos da Lipp e um Questionário semiestruturado organizado pelos próprios autores.

$\begin{array}{lll}\text { - Excesso de trabalho; } & \text { - Bom } & \text { - Ampliação da } \\ \text { - Desrespeito por parte dos } & \text { relacionamento } & \text { atenção na saúde do } \\ \text { alunos e alguns pais; } & \text { entre os pares e } & \text { professor; }\end{array}$

- Falta de um plano de carreira; gestão;

Fonte: Autores.

\section{Discussão}

O estresse refere-se a um estado de tensão, na parte interna do organismo, sendo que em sua fase inicial, apresenta 
alguns sinais e sintomas. O organismo sempre estará em busca do equilíbrio, ocorrendo uma atenção especial ou uma resposta adequada para estabelecer a homeostase anterior. Por tais razões, é importante saber que o desgaste e utilização de reservas de energia são físicos e mentais (Oliveira et al., 2017).

O estresse é um componente específico a toda doença, que produz mudanças na estrutura e na composição química do corpo, as quais podem ser observadas e determinadas, envolvendo fatores bioquímicos, físicos e psicológicos provocando a partir de estímulos externos e internos, sendo capaz de ser identificado e classificado em fases resultantes do organismo (Santiago, Pinto, Dosea, Moccillin, \& Silveira, 2016).

Portanto o organismo deve se adaptar e sobreviver em diferentes situações, podendo ter resultados fatais quando se torna crônico. Qualquer ambiente pode ser fonte geradora de estresse, da qual variam entre os indivíduos, independentemente do nível socioeconômico. Ele por sua vez é reconhecido como fator de risco de alterações negativas no estilo de vida. Os hábitos não saudáveis obtidos incluem aumento na ingestão de: carboidratos, cafeína, tabaco, substâncias psicoativas e/ou tranquilizantes, expondo todos a diversos problemas de saúde (Nascimento, Silva, \& Colares, 2017).

A respeito do estresse e carreira, é importante observar também o conhecimento do potencial estressante sobre algumas profissões reveladas por alguns estudos. A partir da visão mostra-se cerca de 26 profissões, identificadas pelos trabalhadores como eventualmente estressantes. Os pesquisadores identificaram três fatores estressantes: bem-estar psicológico, saúde física e satisfação no trabalho (Trevisan Veloso, Silva, \& Dutra, 2016).

O estudo confirmou a concentração desses três fatores, em seis profissões: trabalhadores de ambulância, professores, trabalhadores de serviço social, trabalhadores de serviço de atendimento ao consumidor, trabalhadores em estabelecimentos prisionais e policiais. Os pesquisadores analisaram que as demais ocupações estudadas não apresentavam tão forte concentração quanto essas seis (Trevisan Veloso, Silva, \& Dutra, 2016).

Na outra ponta estão os fatores de proteção, e dentre eles a família realiza um papel importante, pois é assim que o indivíduo cresce, é cuidado, nutrido, e adquire conhecimento de si mesmo, desenvolve as suas ideias e valores a respeito do mundo e onde é preparado para enfrentar a vida. Portanto, quando um indivíduo tem um transtorno mental, independente da sua fase de desenvolvimento, é interessante ter o apoio da família em seu tratamento (Nascimento, Kolhs, Mella, Berra, Olschowsky, \& Guimarães, 2016).

Em razão disso, a família busca atender as necessidades da pessoa com transtorno de estresse excessivo, principalmente tendo paciência no relacionamento, tendo que vivenciar e aprender a lidar com a situação. A paciência é uma importante ferramenta no processo de cuidar. Por fim, esse sentimento de responsabilidade pelo cuidado do familiar é passado de geração a geração para combater o estresse (Nascimento, Kolhs, Mella, Berra, Olschowsky, \& Guimarães, 2016).

O Brasil tem dois milhões de professores na Educação Básica, com a grande maioria trabalhando na rede pública de ensino (76,8\%) e tendo como parte maior na área urbana (84,5\%). O Ensino Fundamental 2 ( $6^{\circ}$ ao $9^{\circ}$ ano) tem uma porcentagem mais alta ao número de professores (quase 800 mil). De fato, essa população, em específico a da rede pública de ensino, convive com a impressão de diminuição profissional, tendo em vista que a violência aumenta cada vez mais, as condições físicas e impróprias, a perda dos recursos didáticos e a dificuldade de informações. Por sua vez, esses são alguns fatores que podem interferir na qualidade de vida dos profissionais levando a um estresse intenso (Pinto, Senna, Vasconcelos, Leal, Sants, \& Sousa, 2018).

Tendo como característica solitária sua jornada de trabalho, a invasão em sua vida pessoal, interrompendo as noites de sono, o convívio familiar e lazer, tornando-se dessa forma, o surgimento do estresse, envolvendo assim a sua saúde. A partir disso, o professor apresenta ser um profissional submetido a alguns agentes estressores. Ainda que o estresse seja pouco notado, o ambiente educacional gera sobrecargas que ultrapassam os limites, por meio de fatores que podem ou não ser controlados. Dentre estes, destacam-se o ambiente de trabalho hostil, o número elevado de alunos, a quantidade de classes regida e a violência 
no ambiente de trabalho, além de fatores laborais, comportamentais, estruturais, problemas organizacionais, como a falta de recursos e equipamentos, déficit no suporte do governo e salários defasados, em associação com a alta carga de trabalho. Quando não são de fato controlados, provocam a sensação de ameaça e descontrole, promovendo o estresse (Santiago, Pinto, Dosea, Moccillin, \& Silveira, 2016).

É fato que o estresse do professor causa grandes prejuízos na área psicológica e social, interferindo assim diretamente no processo de ensino aprendizagem já que, em descontrole, ele tem dificuldade para motivar seus alunos e manter uma relação de afetividade necessária. Encontrar formas de amenizar esse desequilíbrio pode ajudar a melhorar a qualidade de vida desses profissionais, favorecendo diretamente a relação professor-aluno e o processo de ensino aprendizagem (Pinto, Senna, Vasconcelos, Leal, Sants, \& Sousa, 2018).

Ao analisar os fatores de risco para desenvolvimento do estresse em professores do ensino fundamental, os artigos expõem, com maior incidência, baixo salário, seguido por: indisciplina dos alunos, excesso de trabalho, superlotação das salas, jornada excessiva, cobranças curriculares, desvalorização da figura do docente, falta de apoio familiar, violência explícita, falta de estrutura física, exaustão emocional, falta de concentração, assédio moral, distúrbios de voz, frustação, perda da capacidade de completar o trabalho, transtorno mental comum, alunos não prestam atenção, sintomas osteomusculares, falta de apoio da instituição escolar, doenças psicossomáticas, cansaço excessivo, falta de tempo, falta de plano de carreira, dificuldade em conciliar vida pessoal e profissional.

A sobrecarga de horas e a baixa remuneração têm implicações prejudiciais sobre as condições de trabalho e de saúde dos educadores, uma vez que aguça as condições já estressantes do trabalho realizado, inclusive nas férias e nos finais de semana, retirando do docente a oportunidade de estar com os seus familiares ou amigos e comprometendo sua qualidade de vida (Correa \& Leão, 2020).

Percebe-se que os professores passam por diversos estressores, que estão diariamente os acompanhando e que perpassam as mais diversas ordens como: salas super lotadas, indisciplina dos alunos, falta de estrutura física e material, falta de atenção e compromisso dos alunos com a escola, fazendo com que se sintam desvalorizados, desrespeitados e muitas vezes culpabilizados, por não darem conta de abarcar todas as funções que lhe são impostas. Essas condições de trabalho, nas quais os professores usam de todas as suas capacidades físicas, cognitivas e afetivas para atingir os objetivos da produção escolar podem acabar gerando um grande esforço de suas funções psicofisiológicas (Lucena \& Freitas, 2020).

Analisando todos esses dados, é possível inferir que condições de administração do trabalho, com a intensificação da jornada, as insatisfatórias e desarticuladas políticas de promoção de saúde, perpetuam um ciclo de adoecimento físico e mental nesses profissionais (Santos, Espinosa, \& Marcon, 2020).

Em contrapartida, existem fatores que protegem os professores quanto ao desenvolvimento de estresse, os mais citados são: bom relacionamento entre os pares, valorização, respeito, apoio da família, gostam do alunado, saber conciliar trabalho com vida pessoal, melhoria nas condições de trabalho, não existem discussões, se sentem acolhidos pela escola e melhoria nas relações interpessoais.

Segundo a fala de alguns professores, apesar de todos contratempos enfrentados por eles, muitos ainda se sentem acolhidos pela escola, gostam do alunado, dos seus pares, caracterizando seu ambiente de trabalho como calmo, sem histórico de brigas e discussões (Lucena \& Freitas, 2020).

Outro fator de proteção bastante utilizado pelos professores é a organização do trabalho, os dados coletados apontaram para uma prática docente cortada pela instabilidade e o constante gerenciamento das adversidades, onde as situações de trabal ho e os excesso das atribuições no cotidiano da escola, impõem uma reinvenção diária que contemple o fazer técnico e o cuidado humano nas relações que transbordam o fazer profissional (Lourenço, Valente, \& Correa, 2020).

Ainda falando sobre fatores de proteção, professores sinalizam os fatores que promovem o seu bem-estar como sendo 
respeito, apoio da família, carga horária que possibilite tempo para o planejamento, reconhecimento e valorização, cooperação entre os pares, condições de trabalho, aprendizagem dos alunos e, não menos importante, a formação ou aperfeiçoamento que realizam (Moreira \& Pieve, 2020).

Observamos ainda na pesquisa que professores dizem que o relacionamento entre os pares e com a gestão é bom, e esse fator é de suma importância para a saúde mental dentro de uma instituição escolar. Fazer exercícios físicos é de substancial importância para enfrentar o estresse (Correa \& Leão, 2020).

As estratégias de enfrentamento são os esforços cognitivos e comportamentais para lidar com situações de dano, de ameaça ou de desafio.

Ao analisar as estratégias de enfrentamento citadas pelos professores nos artigos deste trabalho, as mais recorrentes são: ter autocontrole, praticar atividades físicas, ouvir músicas, fazer terapia e ampliação da atenção na saúde do professor.

Esse estudo procura promover o conhecimento de como os professores podem utilizar estratégias para se proteger dos fatores estressantes, o autocontrole foi um dos citados. Segundo os docentes, parar e analisar a situação, falar baixo com os alunos, respirar fundo, dialogar, mudar os alunos de lugar e manter a autoridade dentro da sala de aula, ajudam a diminuir ou regular a sensação causada pelo estresse (Lucena \& Freitas, 2020).

Outra estratégia para enfrentar o estresse é a terapia pois, visam a melhoria das condições de saúde e bem-estar dos docentes, incluindo intervenções que promovam espaço de discussão coletiva e criação de estratégias que ajudem a encontrar o prazer no local de trabalho e valorização profissional (Lourenço, Valente, \& Correa, 2020).

Portanto, é necessário voltarmos o olhar para a saúde mental desses profissionais tão importantes para nossa sociedade

\section{Considerações Finais}

Observamos que o estresse em professores do ensino fundamental é real, e pode levar a sério problemas de saúde mental e física desses profissionais.

Os fatores de riscos relacionados nesses artigos pelos professores são: baixo salário, indisciplina dos alunos, excesso de trabalho, superlotação das salas, jornada excessiva, cobranças curriculares, desvalorização da figura do docente, falta de apoio familiar, violência explícita, falta de estrutura física, exaustão emocional, falta de concentração, assédio moral, distúrbios de voz, frustação, perda da capacidade de completar o trabalho, transtorno mental comum, alunos não prestam atenção, sintomas osteomusculares, falta de apoio da instituição escolar, doenças psicossomáticas, cansaço excessivo, falta de tempo, falta de plano de carreira, dificuldade em conciliar vida pessoal e profissional.

Os fatores de proteção relacionados pelos professores nesses artigos são: bom relacionamento entre os pares, valorização, respeito, apoio da família, gostam do alunado, saber conciliar trabalho com vida pessoal, melhoria nas condições de trabalho, não existem discussões, se sentem acolhidos pela escola e melhoria nas relações interpessoais.

E as estratégias de enfrentamento são: ter autocontrole, praticar atividades físicas, ouvir músicas, fazer terapia e ampliação da atenção na saúde do professor.

\section{Referências}

Brasil. Ministério da Saúde. (2014). Diretrizes metodológicas: Sistema GRADE - Manual de graduação da qualidade da evidência e força de recomendação para tomada de decisão em saúde. Brasília, Ministério da Saúde.

Cardoso, J. V., Gomes, C. F. M., Pereira Junior, R. J., \& Silva, D. A. (2019). Estresse em estudantes universitários: uma abordagem epidemiológica. Revista de enfermagem da UFPE, 13, e241547. https://dx.doi.org/10.5205/1981-8963.2019.241547

Carlotto, M. S., Dias, S. R. S., Batista, J. B. V., \& Diehl, L. (2015). O papel mediador da autoeficácia na relação entre a sobrecarga de trabalho e as dimensões de Burnout em professores. Psico-USF, 20(1), 13-23. https://doi.org/10.1590/1413-82712015200102 
Correa, G. A., \& Leão, M. A. G. (2020). A prática do esporte como estratégia de enfrentamento do estresse docente. Revista Educação e Cultura Contemporânea, 17(49), 336-354. https://dx.doi.org/10.5935/2238-1279.20200064

Gomes, C. F. M., Pereira Junior, R. J., Cardoso, J. V., \& Silva, D. A. da. (2020). Transtornos mentais comuns em estudantes universitários: abordagem epidemiológica sobre vulnerabilidades. SMAD Revista Eletrônica Saúde Mental Álcool E Drogas (Edição Em Português), 16(1), 1-8. https://doi.org/10.11606//issn.1806-6976.smad.2020.157317

Lipp, M. E. N., Costa, K. R. S. N., \& Nunes, V. O. (2017). Estresse, qualidade de vida e estressores ocupacionais de policiais: sintomas mais frequentes. Revista Psicologia Organizações e Trabalho, 17(1), 46-53. https://dx.doi.org/10.17652/rpot/2017.1.12490

Lourenço, V. P., Pérez-Nebra, A. R., Ferreira, A. I., \& Kohlsdorf, M. (2020). Relação entre presenteísmo, síndrome de burnout e liderança ética em organizações escolares. Fractal: Revista de Psicologia, 32(spe), 218-226. https://dx.doi.org/10.22409/1984-0292/v32_i-esp/40568

Lourenço, V. R., Valente, G. S. C., \& Correa, L. V. (2020). Influências do trabalho na saúde mental docente da escola pública do Rio de Janeiro. Research, Society and Development, 9(6), e50963250. http://dx.doi.org/10.33448/rsd-v9i6.3250

Lorenzo, S. M., Alves, A. P. R., \& Silva, N. R. (2020). Burnout e satisfação no trabalho em professores do ensino infantil. Brazilian Journal of Development, 6(5), 26937-26950. https://dx.doi.org/10.34117/bjdv6n5-226

Lucena, H. C., \& Freitas, C. S. C. (2020). Estratégias de enfrentamento utilizadas por professores do ensino médio em situação de estresse. Revista Educação, Psicologia e Interfaces, 4(2), 135-149. https://doi.org/10.37444/issn-2594-5343.v4i2.234

Moreira, E. F., \& Pieve, M. G. P. (2020). Ser professor na contemporaneidade: evidências e percepções do bem/ mal-estar docente em escolas públicas de Cruz Alta. Revista do Seminário de Educação de Cruz Alta - RS, 7(1), 282-289.

Nascimento, K. C., Kolhs, M., Mella, S., Berra, E., Olschowsky, A., \& Guimarães, A. N. (2016). O desafio familiar no cuidado às pessoas acometidas por transtorno mental. Revista de enfermagem da UFPE, 10(3), 940-948. https://dx.doi.org/10.5205/reuol.8702-76273-4-SM.1003201601

Nascimento, M. G., Silva, T. P. S., \& Colares, V. (2017). Fatores relacionados ao estresse entre universitários de odontologia: revisão sistemática da literatura. RIES, 6(2), 57-72.

Nunes, M., Troyan Junior, I. R., Barreto, W. S., \& França Junior, N. R. (2017). Estresse no ambiente de trabalho dos professores de educação física atuantes no ensino médio da rede estadual do município de Ponta Grossa-PR. Anais da Jornada Científica dos Campos Gerais, 15, 1-3.

Oliveira, E. B., Gallasch, C. H., Silva Junior, P. P. A., Oliveira, A. V. R., Valério, R. L., \& Dias, L. B. S. (2017). Estresse ocupacional e burnout em enfermeiros de um serviço de emergência: a organização do trabalho. Revista enfermagem UERJ, 25, e28842. https://doi.org/10.12957/reuerj.2017.28842

Pereira, É. F., Teixeira, C. S., Andrade, R. D., Bleyer, F. T. S., \& Lopes, A. S. (2014). Associação entre o perfil de ambiente e condições de trabalho com a percepção de saúde e qualidade de vida em professores de educação básica. Cadernos Saúde Coletiva, 22(2), 113-119. https://doi.org/10.1590/1414462X201400020002

Pinotti, S. A. G. (2005). Stress no professor: fontes, sintomas e estratégias de controle. Revista Brasileira Multidisciplinar, 9(2), 207-216. https://doi.org/10.25061/2527-2675/ReBraM/2006.v9i2.276

Pinto, R. H., Senna, S. M., Vasconcelos, E. M. R., Leal, L. P., Sants, C. R., \& Sousa, S. M. (2018). Construção e validade do instrumento para avaliar o estresse em professores. Revista de enfermagem da UFPE, 12(9), 2283-2292.

Ribeiro, L. A. C. (2020). A influência da vulnerabilidade ao estresse em professores da rede pública de Catalão (Dissertação de Mestrado). Universidade Federal de Goiás, Catalão.

Santiago, D. P., Pinto, A. P., Dosea, G. S., Moccillin, A. S., \& Silveira, N. A. (2016). Estresse laboral em professores de Lagarto-SE. Motricidade, 12(S2), 7680 .

Santos, E. C., Espinosa, M. M., \& Marcon, S. R. (2020). Qualidade de vida, saúde e trabalho de professores do ensino fundamen tal. Acta Paulista de Enfermagem, 33, eAPE20180286. https://doi.org/10.37689/acta-ape/2020ao0286

Silva, J. P., \& Fischer, F. M. (2020). Invasão multiforme da vida pelo trabalho entre professores de educação básica e repercussões sobre a saúde. Revista de Saúde Pública, 54, 03. https://doi.org/10.11606/s1518-8787.2020054001547

Silva, J. D., Sadoyama, A. S. P., Sousa, B. M. \& Leal, G. S. Saúde mental na escola: uma análise da relação entre cultura organizacional e estresse. Humanidades \& Tecnologia (FINOM), 24, 1-14.

Trevisan, L. N., Veloso, E. F. R., Silva, R. C., \& Dutra, J. S. (2016) Âncoras de carreira e tecnologia na percepção sobre estresse no ambiente de trabalho. Organizações em contexto, 12(24).

Vaz Serra, A. (2000). A vulnerabilidade ao stress. Psiquiatria Clínica, 21(4), 261-278. 